This is the accepted manusript of the article: Peter Varga, INFLUENCE OF TIDAL FORCES ON THE TRIGGERING OF SEISMIC EVENTS

Appeared in: PURE AND APPLIED GEOPHYSICS, First Online: 10 May 2017.,

pp. 1-9. (2017), ISSN: 0033-4553

Publisher's version:

https://link.springer.com/article/10.1007\%2Fs00024-017-1563-5 


\section{INFLUENCE OF TIDAL FORCES ON THE TRIGGERING OF SEISMIC EVENTS}

Péter Varga

Research Centre for Astronomy and Earth Sciences, Hungarian Academy of Sciences, Geodetic and Geophysical Institute, Kövesligethy Seismological Observatory, Budapest Meredek 181015 Hungary (e-mail: varga@seismology. hu, phone: +36 1 2482204, fax: +36 1 2482301

Erik Grafarend

Department of Geodesy and Geoinformatics, Stuttgart University, Germany, Geschwister-Scholl-Str. 24D, 70174 Stuttgart

\section{Abstract}

Tidal stresses are generated in any three-dimensional body influenced by an external inhomogeneous gravity field of rotating planets or moons. In this paper, as a special case, stresses caused within the solid Earth by the body tides are discussed from viewpoint their influence on seismic activity. The earthquake triggering effect of the Moon and Sun are usually investigated by statistical comparison of tidal variations and temporal distribution of earthquake activity, or with the use of mathematical or experimental modelling of physical processes in earthquake prone structures.

In this study the magnitude of lunirsolar stress tensor in terms of their components along the latitude of the spherical surface of the Earth as well as inside the Earth (up to the core-mantle boundary) were calculated for the PREM (Dziewonski and Anderson,1981). Results of calculations prove that increase of stress as a function of depth reaching a value around some $\mathrm{kPa}$ at the depth of $900-1500 \mathrm{~km}$, well below the zone of deep earthquakes. At the depth of the overwhelming part of seismic energy accumulation (around 50 $\mathrm{km})$ the stresses of lunisolar origin are only $(0.0-1.0) \cdot 10^{3} \mathrm{~Pa}$. Despite the fact that these values are much smaller than the earthquake stress drops (1-30 $\mathrm{MPa}$ ) (Kanamori, 1994) this does not exclude the possibility of an impact of tidal forces on outbreak of seismic events. Since the tidal potential and its derivatives are coordinate dependent and the zonal, tesseral and sectorial tides have different distributions from the surface down to the $\mathrm{CMB}$, the lunisolar stress cannot influence the break-out of every seismological event in the same degree. The influencing lunisolar effect of the solid earth tides on earthquake occurrences is connected first of all with radial stress components acting parallel to the surface of the Earth. The influence of load tides is limited to the loaded area and its immediate vicinity. 


\section{Keywords}

spherical tidal stress tensor, zonal, tesseral and sectorial tides, oceanic tidal load

\section{Historical overview and current research results}

One of the founders of modern seismology professor of mathematics at University of Dijon A. Perrey realized first that the study of seismology needs international cooperation. Thanks to his efforts between 1844 and 1871 a significant, for that time earthquake data set was collected by him in form of "Annual lists of Earthquakes". The total number of earthquakes described and catalogued by him is over 21000 . Perrey completed also regional catalogues. This way he initiated the "seismological geography". Although examination of the temporal distribution of earthquakes has been started already in the eighteenth century (Baldivi in 1703 and Toaldo in 1797) (Davison, 1927) Perrey was the first who recognized regularities in temporal distribution of seismic events. Based on his far from being complete catalogue Perrey (1875) concluded, that the series of earthquake occurrences consist periodicities. According to Davison (1927) he has identified three regularities: earthquakes are more frequent at the syzygies than at the quadratures, they are more frequent at perigee than at apogee and the seismic events are more frequent when the moon is near to the meridian.

Since Perrey's time the problem of tidal triggering is one of the "evergreen" problems of earthquake research. The committee appointed by the French Academy of Sciences (Élie de Beaumont, Liouville and Lamé) reported favourably on Perrey's conclusions, while the other great French seismologist $F$. de Montessus de Ballore (1911) strongly criticised them. A. Schuster (1897) was the first who applied to the study of temporal variation of seismic events the tools of statistics and on this basis he has arrived at an optimistic conclusion: "The reality of the period (i.e. tidal periodicity of earthquake occurrence) would be thereby established beyond reasonable doubt" (Schuster,1911). In his study Cotton suggested tidal stresses in the Earth as a secondary cause of earthquakes and according to him it might be possible to predict earthquake occurrence "with sufficient accuracy" by consideration of the position of the 
Sun and the Moon, what allows "to provide timely warnings of disastrous shocks" (Cotton, 1922).

From the early twentieth century, many researchers have dealt with the relationship between tides and earthquakes, in the hope that this way a tool can be found for a more accurate estimation of earthquake hazard. In addition, study of potential effects of tides may be important for seismology because it modifies the spatial and temporal distribution of earthquakes, distorts the image of the nature of seismo-tectonics, what makes more difficult understanding of the nature of earthquakes. A comprehensive summary of research dealing with tidal triggering of earthquakes and volcanic events during the first nine decades of the twentieth century was summarized and discussed by Emter (1997).

A significant number of recent studies found relationship between the lunisolar effect and temporal distribution of seismicity. Most of them shows this relationship on a regional scale. A number of such previous studies were mentioned in Métivier at al. (2009). Nowadays many papers using significant database and advanced statistical methods discuss relationship between different seismological and tidal phenomena. Vergos et al. (2015) detected evidence for tidal triggering of earthquakes of Hellenic arc, Arabelos et al. (2016) describe lunisolar influence on seismic activity in central Greece. H.-J. Chen et al. (2012) suggest that in case of earthquakes which occurred in Taiwan between 1973 and 2008 "the lunar tidal force is likely a factor in the triggering of earthquakes". According to Cochran et al. (2004) the earth tides can trigger shallow thrust fault seismic events. Wilcock (2009) found weak correlation between tidal influence and earthquake occurrences in continental areas which can be increased in settings influenced by loading effect of oceanic tides. Stroup et al. (2007) conclude that the lunisolar periodic stress changes are dominated by oceanic or by solid earth tide in dependence of the position of seismic source zone relative to the distribution of area loaded by oceanic tidal load. In the same time Métivier et al. (2009) on the basis of study global earthquake activity come to the conclusion that "it is highly probable that the observed triggering is caused by the solid Earth tide rather than by loading from the ocean or atmospheric tides". Tanaka $(2010,2012)$ and Ide et al. (2016) 
found significant lunisolar triggering in case of foreshocks prior Sumatra megathrust earthquakes of 26 December $2004\left(M_{w} 9.0\right), 28$ March $2005\left(M_{w}\right.$ 8.6), 12 September 2007 ( $\left.M_{w} 8.5\right)$, and Tohoku-Oki earthquake (2011, $M_{w}=9.1$ ). $\mathrm{Li}$ and $\mathrm{Xu}$ (2013) has found that seismicity of some provinces of China show higher correlation with lunisolar effect during several years preceding a large (destructive) earthquake than during other times. Chen et al. (2012) in case of Christchurch earthquake (2011, $M_{W}=6.3$ ) found correlation between the aftershock sequence and diurnal tide. In the same time these authors found also global correlation in case of seismic events $M_{s} \geq 7$ since 1900 and semidiurnal tidal wave $\mathrm{M}_{2}$. Examinations carried out by different authors show slight dependence of tidal triggering effect and seismological activity on focal mechanisms. Earlier Heaton (1975) concluded that first of all shallow obliqueslip and dip-slip earthquakes $M \geq 5$ correlate with tidally generated shear stresses (Heaton in 1982 retracted this statement after using an extended earthquake catalogue). Tsuruoka et al. (1995) has found slightly higher probability of earthquake occurrence for normal fault earthquakes. Métivier et al. (2009) found that more tidal triggering is exhibited in case of normal strikeslip faulting than in other cases. It was concluded in a recent paper by Ide et al. (2016), that probability of occurrence of great seismic events are higher "during periods of high tidal stresses"(i.e. during spring tides). Houston (2015) combined seismic data and calculated tidal stress and found rising sensitivity during six large slow-slip events of tremors to lunisolar stresses in Cascadia.

Summarizing the results of the studies detecting significant tidal triggering it can be concluded

- the conclusions are almost exclusively based on statistical investigations, only sometimes supported by schematic seismic source models.

- correlation was found in case of shallow-dipping thrust events in case of earthquakes shallower than $50 \mathrm{~km}$ depth.

- the tides can act only in case of faults that are already close to rupture.

- the normal and shear stress are essential factors of tidal triggering

In the same time many researchers could not detct any significant interdependence between time distribution of tidal force and seismic activity. 
Young and Zürn (1979), Vidale et al. (1998), Stein (2004), Tanaka et al. (2006) could not find statistically significant relationship between tidal force and earthquake activity. Based on their investigations Tormann et al. (2015) concluded that large earthquakes "may not have a characteristic location, size or recurrence interval, and might therefore occur more randomly distributed in time".

To contribute in interpretation of differences of research results the study of equations of lunisolar tidal elastic stress tensor components can be probably helpful because it could explain the differences between the research results. In the present investigation for calculations carried out the mathematical tools of author's former study (Varga and Grafarend, 1996) have been used. Our previously used mathematical procedure and - as will be seen in the following sections - the interpretation of the calculation results we have developed in the following ways:

- magnitudes of stresses caused by the lunisolar effect and by surface load instead of relative units used in our previous paper we expressed in the SI system

- a new interpretation was given for the new numerical results obtained both in case of tidal and load models.

\section{The spherical tidal stress tensor}

With the use of spherical harmonics $Y_{2 i}(\Phi, \lambda)$ (where $\Phi$ and $\lambda$ denotes spherical latitude and longitude) in cases of zonal $(i=0)$, tesseral $(i=1)$ and sectorial $(i=2)$ tides the spherical tidal stress tensor components (Figure 1) on the basis of Varga and Grafarend (1996) can be written in the following forms:

$$
\begin{aligned}
& \sigma_{r r_{i}}(r, \lambda, \Phi)=\frac{(\Lambda+2 \mu) \partial H}{\partial r}+\Lambda\left[\frac{2}{r} H-\frac{n(n+1)}{r^{2}} T\right] \cdot Y_{2 i}(\lambda, \Phi)=\mathrm{N}(\mathrm{r}) \cdot Y_{2 i}(\lambda, \Phi) \\
& \sigma_{\Phi \Phi_{i}}(r, \lambda, \Phi)= \\
& \left\{\Lambda\left[\frac{\partial H}{\partial r}+\frac{2 H}{r}-\frac{n(n+1)}{r^{2}} T\right]+2 \mu \frac{H}{r}\right\} \cdot Y_{2 i}(\lambda, \Phi)+2 \mu \frac{T}{r^{2}} \cdot \frac{\partial^{2} Y_{2 i}(\lambda, \Phi)}{\partial \Phi^{2}}
\end{aligned}
$$




$$
\begin{aligned}
& \sigma_{\lambda \lambda_{i}}(r, \lambda, \Phi)=\left\{\Lambda\left[\frac{\partial H}{\partial r}+\frac{2 H}{r}-\frac{n(n+1)}{r^{2}} T\right]+2 \mu \frac{H}{r}\right\} \cdot Y_{2 i}(\lambda, \Phi)+2 \mu \frac{T}{r^{2}} \times \\
& {\left[\frac{\partial^{2} Y_{2 i}(\lambda, \Phi)}{\partial \lambda^{2}}\left(\cos ^{-2} \Phi\right)+\tan \Phi \frac{\partial Y_{2 i}(\lambda, \Phi)}{\partial \Phi}\right]} \\
& \sigma_{\mathrm{r} \Phi_{i}}(r, \lambda, \Phi)=\frac{\mu}{r}\left[\frac{\partial T}{\partial r}-\frac{2 T}{r}+H\right] \frac{\partial Y_{2 i}(\lambda, \Phi)}{\partial \Phi} \\
& \sigma_{\mathrm{r} \lambda_{i}}(r, \lambda, \Phi)=\frac{\mu}{r}\left[\frac{\partial d_{\mathrm{ri}}(r, \lambda, \Phi)}{\partial \lambda} \frac{1}{\cos \Phi}+r \frac{\partial d_{\lambda \mathrm{i}}(r, \lambda, \Phi)}{\partial r}-d_{\lambda \mathrm{i}}(r, \lambda, \Phi)\right]=\frac{\mu}{r \cos \Phi}\left[\frac{\partial T}{\partial r}-\right. \\
& \left.\frac{2 T}{r}+H\right] \frac{\partial Y_{2 i}(\lambda, \Phi)}{\partial \lambda} \\
& \sigma_{\Phi \lambda_{i}}(r, \lambda, \Phi)=2 \frac{\mu T}{r^{2} \cos \Phi}\left[\frac{\partial^{2}\left(Y_{2 i}(\lambda, \Phi)\right.}{\partial \Phi \partial \lambda}-\tan \Phi \frac{\partial Y_{2 i}(\lambda, \Phi)}{\partial \lambda}\right] \\
& \text { (of course } \left.\sigma_{\mathrm{r} \Phi_{i}}=\sigma_{\Phi r_{i}} ; \sigma_{\mathrm{r}_{i}}=\sigma_{\lambda r_{i}} ; \sigma_{\Phi \lambda_{i}}=\sigma_{\lambda \Phi_{i}}\right)
\end{aligned}
$$

In equations (1)-(6) $H(r)$ and $T(r)$, which are functions of the distance from the Earth centre $(r)$, Lamé parameters $\mu=\mu(r), \Lambda=\Lambda(r)$ and density $\rho=\rho(r)$, describe radial and horizontal elastic deformations within the Earth and at the surface $(r=a)$ they are the Love and Shida numbers $H(a)=h$ and $T(a)=l$.

Since the right hand side of the equation (1) for the radial normal stress is proportional to the equation of boundary condition at $r=a$

$\frac{(\Lambda+2 \mu) \partial H}{\partial r}+\Lambda\left[\frac{2}{a} H-\frac{n(n+1)}{a^{2}} T\right]=0$ implies, that $\sigma_{r r_{i}}(a, \lambda, \Phi)=0$

Similarly at the surface of the Earth $\sigma_{\mathrm{r} \Phi_{i}}(a, \lambda, \Phi)=\sigma_{\mathrm{r} \lambda_{i}}(a, \lambda, \Phi)=0$ whereas the terms in the right side of the equation are proportional to the boundary condition $\mu\left(\frac{\partial T}{\partial r}-\frac{2}{a} T+H\right)=0$ at $r=a$.

Therefore, it can be concluded that three out of six independent components of the stress tensor are zero at $r=a$ and they are not involved into tidal triggering. It can be seen from the results of calculations (see next section) that $\sigma_{\Phi \lambda_{i}}(a, \lambda, \Phi)=0$. That is why the trigger effects at the surface of the Earth $(r=a)$ can be associated only with two radial tensor components $\sigma_{\Phi \Phi_{i}}(a, \lambda, \Phi)$ and $\sigma_{\lambda \lambda_{i}}(a, \lambda, \Phi)$ acting parallel to the surface of the Earth.

\section{Calculation of spherical tidal stress tensor components}


As a first step similarly to the procedure described in Varga and Grafarend (1996), the numerical values of $H(r)$ and $T(r)$ functions were determined for the elastic mantle of the Earth from the surface $(r=a)$ to the core-mantle boundary $(r=b)$. For this purpose the equation of motion introduced by Takeuchi (1953), Molodensky (1953), Alterman et al. (1959) should be used. For the solution Molodensky used auxiliary functions for normal $(N(r))$, tangential $(M(r))$

stresses and gravity potential (Poisson equation) $(L(r))$ :

$$
\begin{gathered}
N=(\Lambda+2 \mu) \partial H / \partial r+\Lambda\left[2 / r H-n(n+1) / r^{2} T\right] \\
M=\mu\left(\frac{\partial T}{\partial r}-\frac{2}{r} T+H\right) \\
L=r^{2}\left(\frac{\partial R}{\partial r}-4 \pi G \rho H\right)
\end{gathered}
$$

In equation (9) $R(a)-l=k$ is the second Love number and $G$ the gravitational constant. In case of calculation of functions $N(r), M(r)$ along the radius at the surface of the Earth $(r=a)$ the boundary conditions are equal to zero: $N(a)=$ $M(a)=L_{n}(a)=0$.

With the use of numerical values of $H(r), T(r), N(r)$, and $M(r)$ in equations (1)-(6) the stress tensor components were calculated in cases of zonal $(i=0)$, tesseral $(i=1)$ and sectorial $(i=2)$ tides, for the latitudes $0^{\circ}, 20^{\circ}, 40^{\circ}$ and $60^{\circ}$ from the surface of the Earth till the core-mantle boundary. The numerical values of Lamé parameters $\mu(r), \Lambda(r), \rho(r)$ for the elastic mantle $(a \geq r \geq b)$ were taken from the PREM (Dziewonski and Anderson, 1981).

The results of computations (Table 1 ) show that

- $\sigma_{\mathrm{r} \lambda_{i=0}}(r, \lambda, \Phi)$ and $\sigma_{\Phi \lambda_{i=0}}(r, \lambda, \Phi)$ are equal to zero from the surface to the core-mantle boundary in case of zonal tides for all latitudes (therefore they are missing from the table)

- at the equator $\left(\Phi=0^{\circ}\right)$ the zonal $\sigma_{\mathrm{r} \Phi_{i=0}}\left(r, \lambda, 0^{\circ}\right)$, the tesseral $\sigma_{r r_{i=1}}\left(r, \lambda, 0^{\circ}\right), \sigma_{\Phi \Phi_{i=1}}\left(r, \lambda, 0^{\circ}\right)$ and $\sigma_{\lambda \lambda_{i=1}}\left(r, \lambda, 0^{\circ}\right)$, and the sectorial $\sigma_{\Phi \lambda_{i=2}}\left(r, \lambda, 0^{\circ}\right), \sigma_{\lambda_{i=2}}\left(r, \lambda, 0^{\circ}\right)$ tensor components have zero value through the mantle

- as it was already mentioned, at the surface of the Earth normal stresses $\sigma_{r r_{i}}(a, \lambda, \Phi)=\sigma_{\mathrm{r} \Phi_{i}}(a, \lambda, \Phi)=\sigma_{\mathrm{r}_{i}}(a, \lambda, \Phi)=0(i=0,1,2)$. The 
same is valid for shear stress: $\sigma_{\Phi \lambda_{i=0}}(a, \lambda, \Phi)=0$. These stress tensor components are negligibly small to depths approximately $200-300 \mathrm{~km}$

- only the horizontal components of the normal stress, $\sigma_{\Phi \Phi}$ and $\sigma_{\lambda \lambda}$, have non zero values at $r=a$, which are $\leq 2 \mathrm{kPa}$.

It can be concluded on these aforementioned conclusions that the influence of the earth tides on earthquake activity is a complex phenomenon. Their impact depends on the geographic location, on the depth and on the direction of stress tensor components. The strongest influence have the zonal (longperiodic) and sectorial (semi-diurnal) tides on $\sigma \varphi \varphi$ and $\sigma \lambda \lambda$ (Figure 2, Table 2). Their largest magnitude ( $1 \mathrm{kPa})$ can be observed in the equatorial region and at high latitudes. In contrast the tesseral (diurnal) tides have less triggering effect as the two aforementioned ones.

\section{Spherical stresses produced by oceanic load}

The calculation of the functions $H^{\prime}(r)$ and $T^{\prime}(r)$ of external (relative to the solid Earth) load is similar to the case of the lunisolar effect, but the surface boundary conditions are modified: two of them remain the same as in case of earth tides: $M^{\prime}(a)=L^{\prime}(a)=0$, but the third one expresses that the loading mass is on the surface of the Earth: $N^{\prime}(a)=p=\rho^{*} g h$, where $p$ is the surface pressure, $\rho^{*}$ is the density of sea water $\left(1025 \mathrm{~kg} / \mathrm{m}^{3}\right)$ and $h$ is tidal height in $\mathrm{m}$. Because $N^{\prime}(a) \neq 0$ consequently $\sigma_{r r}(a) \neq 0$ (see equation (1)). The gravitational potential of a rectangular spheroidal layer on the surface at a spherical distance from the centre of the loaded $\theta$, characterised by a centri angle $\alpha$ after Pertzev (1976) can be given in the following form:

$W(\Theta)=\sum_{n=1}^{\infty} W_{n}=\frac{2 \pi G a}{g} \sum_{n=1}^{\infty} \frac{1}{2 n+1}\left[P_{n-1}(\cos \alpha)-P_{n+1}(\cos \alpha)\right] P_{n}(\cos \Theta)\left(\frac{r}{a}\right)^{n}$

Similarly to the earth tidal stress tensor can be obtained the load stress tensor, considering that the surface load is axially symmetric, and therefore the solution does not depend on the azimuth (Varga and Grafarend, 1996):

$$
\begin{aligned}
& \sigma_{r r}=\sum_{n=1}^{\infty} N_{n}^{\prime} W_{n}(\Theta)\left(\frac{r}{a}\right)^{n} \\
& \sigma_{\Theta \Theta}=\sum_{n=1}^{\infty}\left\{\left[\Lambda\left(\frac{\partial H_{n}^{\prime}}{\partial r}+\frac{2 H_{n}^{\prime}}{r}-\frac{n(n+1)}{r^{2}} T_{n}^{\prime}\right)+2 \mu \frac{H_{n}^{\prime}}{r}\right] W_{n}(\Theta)+2 \mu \frac{T_{n}^{\prime} \frac{\partial W_{n}}{\partial \Theta}}{r^{2}}\right\}\left(\frac{r}{a}\right)^{n}
\end{aligned}
$$


$\sigma_{\lambda \lambda}=\sum_{n=1}^{\infty}\left\{\left[\Lambda\left(\frac{\partial H_{n}^{\prime}}{\partial r}+\frac{2 H_{n}^{\prime}}{r}-\frac{n(n+1)}{r^{2}} T_{n}^{\prime}\right)+2 \mu \frac{H_{n}^{\prime}}{r}\right] W_{n}(\Theta)+2 \mu T_{n}^{\prime} \tan \Theta \frac{\partial W_{n}}{\partial \Theta}\right\}\left(\frac{r}{a}\right)^{n}$

$\sigma_{r \Theta}=\sum_{n=1}^{\infty} \frac{M_{n}^{\prime}}{r} \frac{\partial W_{n}(\Theta)}{\partial \Theta}\left(\frac{r}{a}\right)^{n}$

$\sigma_{r \lambda}=0$

$\sigma_{\Theta \lambda}=0$

Equations (11)-(16) show that the load generated stress is mainly radial $\left(\sigma_{r r}, \sigma_{\Phi \Phi}\right.$ and $\left.\sigma_{\lambda \lambda}\right) . \sigma_{r \theta}=0$, while $M^{\prime}(a)=0$. The magnitude of $\sigma_{r r}$ is significant only locally, in the middle of the loaded area it may reach $100 \mathrm{kPa}$ in case of $1 \mathrm{~m}$ high oceanic tide and on area $10^{\circ} \cdot 10^{\circ}\left(\sim 10^{6} \mathrm{~km}^{2}\right)$, while the other two radial components $\sigma_{\Phi \Phi}$ and $\sigma_{\lambda \lambda}$ are $30 \mathrm{kPa}$ (Figure 3). If the area of tidal load is reduced the amplitude of the load stress is also decreases. According to model calculations carried out: the amplitudes of the load in case of spherical segments $5^{\circ} \cdot 5^{\circ}\left(\sim 2.5 \cdot 10^{5} \mathrm{~km}^{2}\right)$, and $2^{\circ} \cdot 2^{\circ}\left(\sim 4 \cdot 10^{4} \mathrm{~km}^{2}\right)$ are $25 \%$ and $7 \%$ of the amplitude obtained for spherical segment $10^{\circ} \cdot 10^{\circ}$. In the immediate vicinity of the loaded area the magnitude of load stress is (30-40) \% of the maximum obtained for the middle of the loaded area. In contrast to the tidal stress, which inside the Earth moving away from the surface significantly increases its value (Table 3), the magnitude of the load stress decreases with depth rapidly.

\section{What is the impact of the earth and oceanic tides on earthquake activity?}

The results of the calculations show that in case of all tide types (zonal, tesseral, and sectorial) the stress components significantly increase with depth, but not approaching their maximum values in the depth range of interest from the viewpoint of earthquakes. The deepest earthquake focal depth data reliably determined is $684 \pm 10 \mathrm{~km}$ (South of Fiji, 17 June 1977). The radial and shear stress components show a monotonous increase at least until the middle of the mantle between 1000 and $2000 \mathrm{~km}$ depth zone (0.85-0.70 r/a). Moreover some stress types reach their maximum value in this depth range. Results of model calculations show that distribution of tidal stress tensor components up to $1000 \mathrm{~km}$ depth not depends to a substantial degree on the inner structure of the Earth. The distribution was compared in case of PREM and a model of the Earth with homogeneous mantle where the density 
depends only on the hydrostatic pressure. The biggest observed difference did not exceed 20 per cent.

The depth distribution of stresses has a minor importance for study possible tidal triggering, since $95 \%$ of the seismic energy is released within the depth interval (0-50) km (Varga et al., 2017). As it was shown in Section 2 the role of lunisolar effect can be significant in case of horizontal shear stresses $\sigma_{\Phi \Phi}$ and $\sigma_{\lambda \lambda}$. The likelihood of triggering effect in case of shallow seismicity in all probability can increase the fact, that the majority of the forces generating earthquakes are horizontal (or nearly horizontal) (e.g. normal, reverse or strike slips). If we accept that these two stress types may be the most conceivable earth tidal agents, we must also take into account that the geographical distribution of $\sigma_{\Phi \Phi}$ and $\sigma_{\lambda \lambda}$ is diversified. In equatorial area there is no triggering by tesseral tides, but the sectorial and zonal tides are big. At midlatitudes the zonal tide generated stresses are missing, while in polar regions only the zonal stress tensor component are significant.

Stresses produced by surface load are generated directly on the loaded area or in its immediate vicinity. Despite of the fact that tide generating load can be sometimes very significant, it has a local effect only (Figure 3 ). If a huge area of about one million square kilometres $\left(\sim 10^{\circ} \times 10^{\circ}\right)$ is loaded by $1 \mathrm{~cm}(100 \mathrm{~Pa}, 10$ mbar) high tide only the generated vertical ( $\sigma_{r r}$ ) and horizontal $\left(\sigma_{\theta \theta}\right)$ stresses are $1,13 \mathrm{kPa}$ and $0.48 \mathrm{kPa}$ only (Table 3 , Figure 3 ). Of course in case of $1 \mathrm{~m}$ high tide the generated stresses are of the order of $10^{-1} \mathrm{MPa}$, what is still very little amount in comparison with the accumulated energy in earthquake foci of significant seismic events $\left(10^{5} \mathrm{~Pa}-10^{7} \mathrm{~Pa} ; 1 \mathrm{bar}-10 \mathrm{bar}\right)$. Of course the area of $10^{\circ} \times 10^{\circ}$ is very high. In case of $1^{\circ} \times 1^{\circ}$ the $100 \mathrm{~Pa}$ load generates stresses about ten times smaller. As it was mentioned already earthquakes are shear fracture processes and consequently they are controlled predominantly by maximum stresses. Therefore -as in the case of tidal stress-for triggering the horizontal load stress $\left(\sigma_{\theta \theta}\right)$ is of importance.

\section{Summary}

Reviewing the results of the calculations it can be concluded that the magnitude of triggering effect of earth tides is different in case of zonal, tesseral, and sectorial tides and also significantly depends on the latitude. 
The results of calculations carried out using theoretical models show that only the horizontal shear stresses $\sigma_{\Phi \Phi}$ and $\sigma_{\lambda \lambda}$ produced by earth tides are able to influence the outbreak of earthquake

The load caused by oceanic tides due to their local influence on solid Earth has only a limited role in earthquake triggering by tides.

\section{Acknowledgements}

We thank our reviewers ( Walter Zürn and an anonymous colleague) for their helpful comments.

The research described in this paper was completed during research stay of $P$. Varga (01.03.2016-31.05.2016) supported by the Alexander Humboldt Foundation at the Department of Geodesy and Geoinformatics, Stuttgart University. P. Varga thanks Professor Nico Sneeuw for the excellent research conditions provided by him.

Financial support from the Hungarian Scientific Research Found OTKA (Project K125008) is acknowledged.

\section{REFERENCES}

Alterman, Z., Jarosch, H.,\& Pekeris, C.L. (1959) Oscillations of the Earth, Proceedings of the Royal Society London A, 252, 80-95

Arabelos, D.N., Contadakis, M.E., Vergos, G., \& Spatalas, S. (2016) Variation of the Earth tide-seismicity compliance parameter during the recent seismic activity in Fthiotida, central Greece, Annals of Geophysics, 59, 1, S0102; doi:10.4401/ag-6795

Chen, H.-J., Chen, C.-Y., Tseng, J.-H., \& Wang, J.-H. (2012) Effect of tidal triggering on seismicity in Taiwan revealed by the empirical mode decomposition method, Natural Hazards and Earth System Sciences, 12, 2193-2202

Chen, L., Chen, J.G., \& Xu, Q.H. (2012) Correlation between solid tides and worldwide earthquakes $M \geq 7$ since 1900, Natural Hazards and Earth System Sciences, 12, 587-590

Cochran, E.S., Vidale, J.E.,\& Tanaka, S. (2004) Earth tide can trigger shallow thrust fault earthquakes, Science, 306, 1164-1166

Cotton, L.A. (1922) Earthquakefrequency with special refernce to tidal stresses in the lithosphere, Bulletin of the Seismological Society of America, 12, 47-198 
Davison, C. (1927) Founders of seismology, Cambridge University Press

Dziewonski, A.M., \& Anderson, D. L. (1981) Preliminary reference Earth model, Physics of the Earth and Planetary Interiors. 25, 4, 297-356.

Emter D. (1997) Tidal triggering of earthquakes and volcanic events. In: Tidal Phenomena, Lecture Notes in Earth Sciences, 66 (Eds. Wilhelm H., ZürnW., Wenzel H.G.), Springer, Heidelberg, 293-309

Grafarend, E. (1986) Three-dimensional deformation analysis: global vector spherical harmonic and local finite element representation, Tectonophysics, 130, 1-4, 337-359

Heaton, T.H. (1975) Tidal triggering of earthquakes, Geophysical Journal of the Royal Astronomical Society, 43, 307-326

Heaton, T.H. (1982) Tidal triggering of earthquakes, Bulletin of the Seismological Society of America, 72, 6, 2181-2200

Houston H. (2015) Low friction and fault weakening revealed by rising sensitivity of tremor to tidal stress, Nature Geoscience, 8, 409-415

Ide, S., Yabe, S., \& Tanaka Y. (2016) Earthquake potential revealed by tidal influence on earthquake size-frequency statistics, Nature Geoscience, doi:10.1038/ngeo2796

Kanamori, H. (1994) Mechanics of Earthquakes, Annual Reviwes of Earth and Planetary Sciences, 22, 207-237

Li, Q., \& Xu, G-M. (2013) Precursory pattern of tidal triggering of eartquakes, Natural Hazards and Earth System Sciences, 13, 2605-2618

Métivier, L., de Viron, O., Conrad, C.P., Renault, S., Diament, M.,\& Patau G. (2009) Evidence of earthquake triggering by the solid earth tides, Earth and Planetary Science Letters, 278, 370-375

Molodensky, M. S. (1953) Elastic tides, free nutations and some questions concerning the inner structure of the Earth, Trudi Geofizitseskogo Instituta Akademii Nauk of the USSR, , 19 (146), 3-42.

Montessus de Ballore, F. (1911) La sismologie moderne: les tremblements de terre, Libraire A, Colin

Pertzev, B.P. (1976) Influence of the oceanic tides, Physics of the Solid Earth, 1, 13-27

Perrey, A. (1875) Sur la fréquences des tremblements de terre relativement a l'age de la lune, Comptes Rendus hebdomadaires des séances de la Académie des Sciences, 81, 690692

Schuster, A. (1897) On lunar and solar periodicities of earthquakes. Proceedings of the Royal Society of London, 61, 455-465 
Schuster, A. (1911) Some problems of seismology, Bulletin of the Seismological Society of America, 1, 97-100

Stein R.S. (2004) Tidal triggering caught in the act, Science, 305,5688, 1248-1249, DOI: 10.1126/sciencee.1100726

Stroup, D.F., Bohnenstiehl, D.R., Tolstoy, M., Waldhauser, F., \& Weekly R. T. (2007) Pulse of the seafloor: Tidal triggering of microearthquakes at $9^{\circ} 50^{\circ} \mathrm{N}$ East Pacific Rise, Geophysical Research Letters, 34, L15301, doi:10.1029/2007GL030088.

Takeuchi H. (1953) On the earth tide of the compressible earth of variable density and elasticity, Transactions American Geophysical Union, 31 (5), 651-689.

Tanaka, S., Sato, H., Matsumura, S., \& Ohtake M. (2006) Tidal triggering of earthquakes in the subducting Philippine sea plate beneath the locked zone of the plate interface in the Tokai region, Tectonophysics, 417, 69-80

Tanaka, S. (2010) Tidal triggering of earthquakes precursory to the recent Sumatra megathrust earthquakes of 26 December 2004 (Mw 9.0), 28 March 2005 (Mw 8.6), and 12 September 2007 (Mw 8.5), Geophysical Research Letters, 37, 2, DOI: 10.1029/2009GL041581

Tanaka, S. (2012) Tidal triggering of earthquake prior to the 2011 Tohoku-Oki eartquake( $\left.M_{W}=9.1\right)$, Geophysical Research Letters, 39, 7, 10.1029/2012GL051179

Tormann, T., Enescu, B., Woessner, J., \& Wiemer, S. (2015). Randomness of megathrust earthquakes implied by rapid stress recovery after the Japan earthquake. Nature Geoscience, 8, 2, 152-158

Tsuruoka, H., Ohtake, M., \& Sato H. (1995) Statistical test of the tidal triggering of earthquakes: contribution of the ocean tide loading effect, Geophysical Journal International, 122, 1, 183-194

Varga, P., \& Grafarend, E. (1996) Distribution of the lunisolar tidal elastic stress tensor components within the Earth's mantle, Physics of the Earth and Planetary Interiors, 96, 285-297

Varga P., Rogozhin E.A., Süle B., Andreeva N.V., 2017: A study of energy released by great $(M \geq 7)$ deep focus seismic events having regard to the May 24, $2013 \mathrm{Mw} 8.3$ earthquake the Sea of Okhotsk, Russia, Izvestiya, Physics of the Solid Earth (in print)

Vidale, J.E., Agnew, D.C., Johnston, M.J.S., \& Oppenheimer, D.H. (1998) Absence of earthquake correlation with Earth tides: An indication of high preseismic fault stress rate, Journal of Geophysical Research-Solid Earth, 103, 24567-24572.

Vergos, G.S., Arabelos, D., \& Contadakis M.E. (2015) Evidence for Tidal triggering on the earthquakes of the Hellenic Arc, Greece, Physics and Chemistry of the Earth Parts A/B/C, 85-86, 210-215 
Wilcock, W.S.D. (2009) Tidal triggering of earthquakes in the Northeast Pacific Ocean, Geophysical Journal International, 179, 2, 1055-1070

Young, D., Ziirn, W. (1979) Tidal triggering of earthquakes in the Swabian Jura? Journal of Geophysics, 45, 171-182.

\section{TABLE CAPTIONS}

Table 1. Lunisolar zonal, tesseral and sectorial stress tensor components ( in $\mathrm{kPa}$ ) within the mantle at latitudes $0^{\circ}, 20^{\circ}, 40^{\circ}$ and $60^{\circ}$

Table 2. Latitude dependence of the horizontal shear stress tensor components $\sigma \lambda \lambda$ and $\sigma \varphi \varphi$ at the Earth's surface in $\mathrm{kPa}$.

Table 3. Distribution of vertical $\left(\sigma_{r r}\right)$ and horizontal $\left(\sigma_{\theta \theta}\right)$ load stress components (in $\mathrm{kPa}$ ) at the surface in function of angular distance from the centre of the loaded area $10^{\circ} \times 10^{\circ} .10^{2} \mathrm{~Pa}$ load is considered.

\section{FIGURE CAPTIONS}

Figure 1. Stress tensor components. Normal stresses: $\sigma_{r r}, \sigma_{\Phi \Phi,}, \sigma_{\lambda \lambda}$ and shear stresses: $\sigma_{r \lambda}=\sigma_{\lambda r}, \sigma_{r \Phi}=\sigma_{\Phi r}, \sigma_{\Phi \lambda}=\sigma_{\lambda \Phi}$

Figure 2. Latitude dependence of normal horizontal stress tensor components along the surface of the Earth (Z-zonal, T-tesseral and S-sectorial tides)

Figure 3. Radial normal and lateral stress tensor components $\left(\sigma_{r r}, \sigma_{\Theta \Theta}\right)$ caused by $10^{2} \mathrm{~Pa}$ normal load on a spherical segment $10^{0} \times 10^{0}$ in function of spherical distance $\theta$. 
Figure 1.

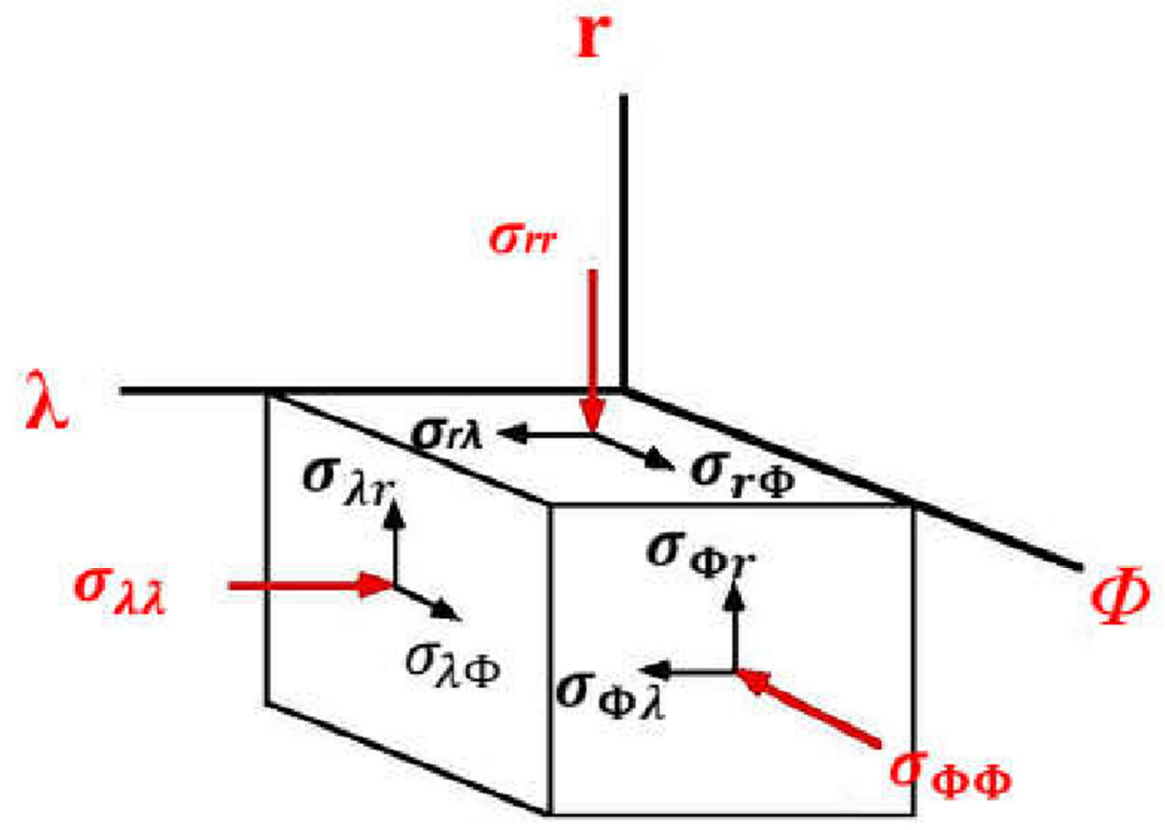

Figure 2 


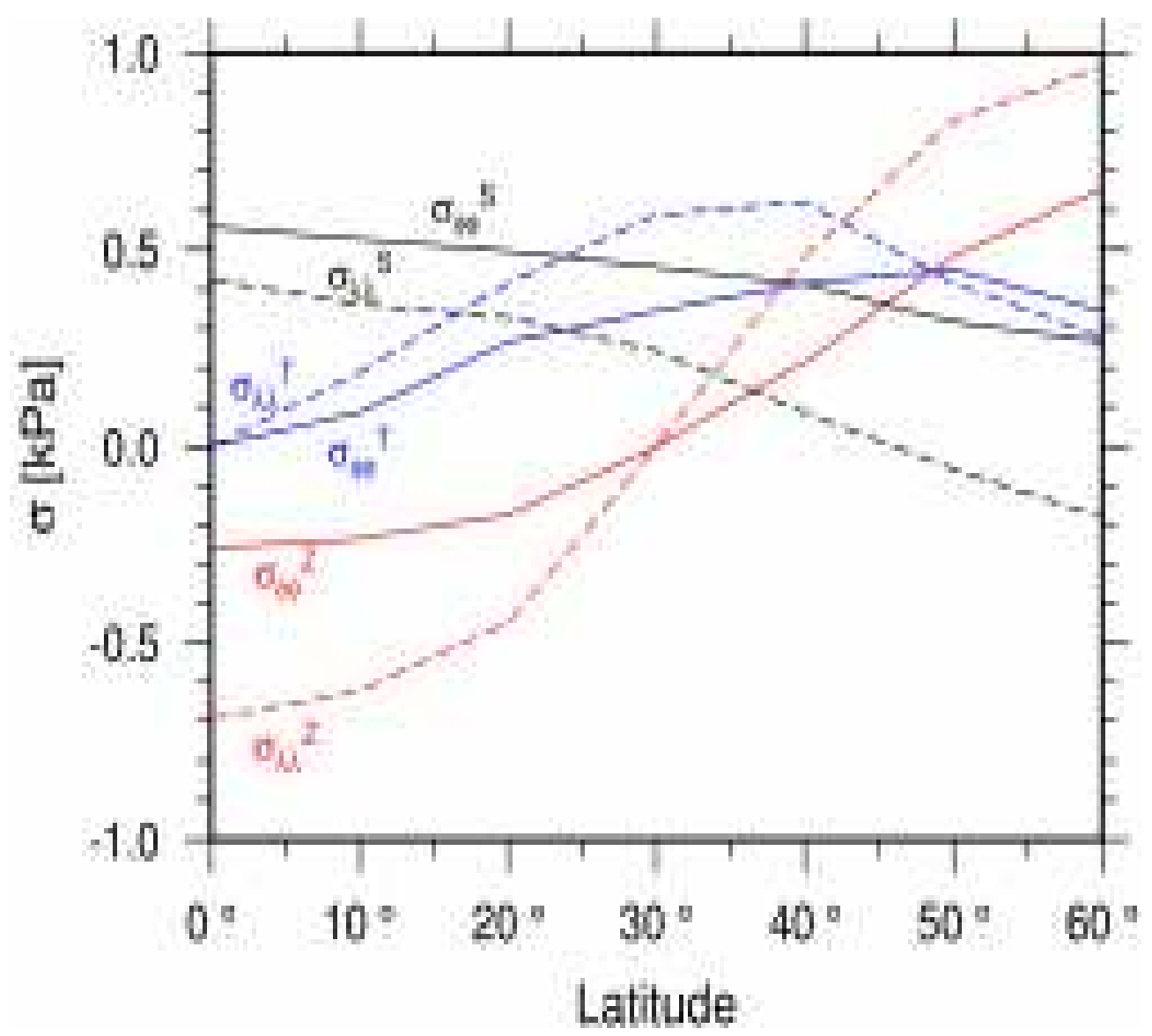

Figure 3 


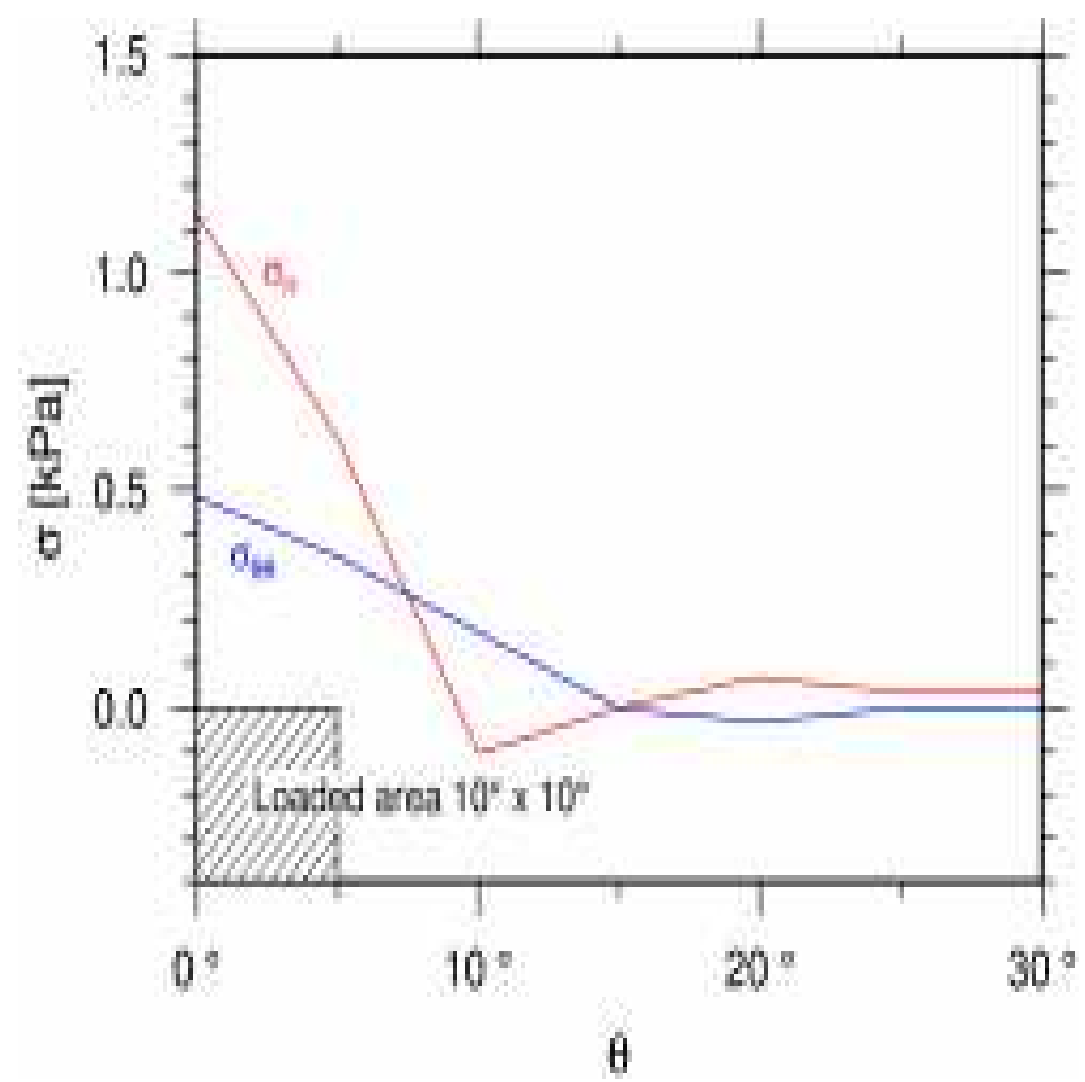

Table 1. Lunisolar zonal, tesseral and sectorial stress tensor components ( in $\mathrm{kPa})$ within the mantle ( $\mathrm{a} \geq \mathrm{r} \geq 0,55$-the approximate radius of the core) at latitudes $0^{\circ}, 20^{\circ}, 40^{\circ}$ and $60^{\circ}$

ZONAL TIDES

\begin{tabular}{|r|r|r|r|r|}
\hline Orr r/a & \multicolumn{1}{|l|}{$0^{\circ}$} & \multicolumn{1}{l|}{$20^{\circ}$} & \multicolumn{1}{l|}{$40^{\circ}$} & \multicolumn{1}{l|}{$60^{\circ}$} \\
\hline 1,00 & 0 & 0 & 0 & 0 \\
\hline 0,90 & $-0,38$ & $-0,24$ & 0,03 & 0,35 \\
\hline 0,80 & $-0,52$ & $-0,35$ & 0,07 & 0,76 \\
\hline 0,70 & $-0,41$ & $-0,28$ & 0,03 & 0,59 \\
\hline 0,60 & $-0,28$ & $-0,14$ & 0,17 & 0,31 \\
\hline 0,55 & $-0,69$ & $-0,35$ & 0,41 & 0,93 \\
\hline
\end{tabular}

\begin{tabular}{|c|c|c|c|c|}
\hline$\sigma r \varphi r / a$ & $0^{\circ}$ & $20^{\circ}$ & $40^{\circ}$ & $60^{\circ}$ \\
\hline 1,00 & 0,00 & 0,00 & 0,00 & 0,00 \\
\hline 0,90 & 0,00 & 0,38 & 0,55 & 0,76 \\
\hline 0,80 & 0,00 & 0,86 & 1,10 & 1,38 \\
\hline 0,70 & 0,00 & 1,21 & 1,66 & 2,00 \\
\hline 0,60 & 0,00 & 0,86 & 1,14 & 1,62 \\
\hline 0,55 & 0,00 & 0,00 & 0,00 & 0,00 \\
\hline
\end{tabular}

\begin{tabular}{|r|c|c|c|c|}
\hline$\sigma \varphi \varphi \mathrm{r} / \mathrm{a}$ & $0^{\circ}$ & $20^{\circ}$ & $40^{\circ}$ & $60^{\circ}$ \\
\hline 1,00 & $-1,83$ & $-0,41$ & 0,07 & 0,69 \\
\hline 0,90 & $-0,52$ & 0,10 & 0,69 & 1,97 \\
\hline
\end{tabular}




\begin{tabular}{|l|l|l|l|l|}
\hline 0,80 & 0,69 & 0,79 & 1,38 & 2,52 \\
\hline 0,70 & 2,83 & 2,76 & 2,66 & 2,35 \\
\hline 0,60 & 9,32 & 7,76 & 3,90 & 0,41 \\
\hline 0,55 & 14,84 & 8,45 & 5,35 & 0,17 \\
\hline
\end{tabular}

\begin{tabular}{|r|c|c|c|l|}
\hline$\sigma \lambda \lambda \mathrm{r} / \mathrm{a}$ & $0^{\circ}$ & \multicolumn{1}{|c|}{$20^{\circ}$} & $40^{\circ}$ & \multicolumn{1}{|c|}{$60^{\circ}$} \\
\hline 1,00 & 0,00 & 0,00 & 0,00 & 1,38 \\
\hline 0,90 & $-2,66$ & $-0,52$ & 1,28 & 4,55 \\
\hline 0,80 & $-3,86$ & $-2,07$ & 2,83 & 12,42 \\
\hline 0,70 & $-4,83$ & $-2,42$ & 5,00 & 16,91 \\
\hline 0,60 & $-4,83$ & $-1,38$ & 7,07 & 17,77 \\
\hline 0,55 & $-4,14$ & $-1,04$ & 7,59 & 18,11 \\
\hline
\end{tabular}

TESSERAL TIDES

\begin{tabular}{|l|l|l|l|l|}
\hline Orr r/a & $0^{\circ}$ & \multicolumn{1}{|c|}{$20^{\circ}$} & $40^{\circ}$ & $60^{\circ}$ \\
\hline 1,00 & 0,00 & 0,00 & 0,00 & 0,00 \\
\hline 0,90 & 0,00 & 0,10 & 0,14 & 0,10 \\
\hline 0,80 & 0,00 & 0,31 & 0,55 & 0,38 \\
\hline 0,70 & 0,00 & 0,21 & 0,48 & 0,41 \\
\hline 0,60 & 0,00 & 0,21 & 0,28 & 0,24 \\
\hline 0,55 & 0,00 & 0,31 & 0,55 & 0,41 \\
\hline
\end{tabular}

\begin{tabular}{|r|l|r|r|r|}
\hline$\sigma r \varphi \mathrm{r} / \mathrm{a}$ & $0^{\circ}$ & \multicolumn{1}{c|}{$20^{\circ}$} & $40^{\circ}$ & \multicolumn{1}{c|}{$60^{\circ}$} \\
\hline 1,00 & 0,00 & 0,00 & 0,00 & 0,00 \\
\hline 0,90 & 0,48 & 0,41 & 0,17 & $-0,28$ \\
\hline 0,80 & 1,04 & 0,76 & 0,28 & $-0,66$ \\
\hline 0,70 & 1,41 & 1,17 & 0,35 & $-0,83$ \\
\hline 0,60 & 1,10 & 0,76 & 0,10 & $-0,59$ \\
\hline 0,55 & 0,00 & 0,00 & 0,00 & 0,00 \\
\hline
\end{tabular}

\begin{tabular}{|r|c|l|l|l|}
\hline$\sigma \varphi \varphi \mathrm{r} / \mathrm{a}$ & $0^{\circ}$ & \multicolumn{1}{|c|}{$20^{\circ}$} & $40^{\circ}$ & $60^{\circ}$ \\
\hline 1,00 & 0,00 & 0,28 & 0,41 & 0,35 \\
\hline 0,90 & 0,00 & 0,59 & 0,83 & 0,59 \\
\hline 0,80 & 0,00 & 0,41 & 0,66 & 0,48 \\
\hline 0,70 & 0,00 & 0,07 & 0,10 & 0,14 \\
\hline 0,60 & 0,00 & $-1,28$ & $-1,55$ & 1,38 \\
\hline 0,55 & 0,00 & $-3,28$ & $-3,28$ & $-5,35$ \\
\hline
\end{tabular}

\begin{tabular}{|r|c|c|c|c|}
\hline$\sigma \varphi \lambda$ r/a & $0^{\circ}$ & $20^{\circ}$ & $40^{\circ}$ & $60^{\circ}$ \\
\hline 1,00 & 0,00 & 0,00 & 0,00 & 0,00 \\
\hline 0,90 & 0,59 & 0,38 & $-0,10$ & $-1,38$ \\
\hline 0,80 & 1,41 & 0,97 & $-0,24$ & $-3,69$ \\
\hline 0,70 & 2,76 & 1,62 & $-0,35$ & $-6,04$ \\
\hline 0,60 & 4,04 & 2,76 & $-1,38$ & $-7,49$ \\
\hline 0,55 & 5,21 & 3,28 & $-1,62$ & $-8,18$ \\
\hline
\end{tabular}

\begin{tabular}{|r|l|r|r|r|}
\hline$\sigma \lambda \lambda \mathrm{r} / \mathrm{a}$ & $0^{\circ}$ & \multicolumn{1}{c|}{$20^{\circ}$} & \multicolumn{1}{c|}{$40^{\circ}$} & \multicolumn{1}{c|}{$60^{\circ}$} \\
\hline 1,00 & 0,00 & 0,10 & 0,24 & 0,08 \\
\hline 0,90 & 0,00 & 1,38 & 1,73 & 0,10 \\
\hline 0,80 & 0,00 & 2,42 & 2,76 & $-0,35$ \\
\hline 0,70 & 0,00 & 3,11 & 3,11 & $-2,76$ \\
\hline 0,60 & 0,00 & 3,45 & 1,73 & $-5,87$ \\
\hline 0,55 & 0,00 & 3,11 & 1,21 & $-6,73$ \\
\hline
\end{tabular}

\begin{tabular}{|rc|c|r|r|r|}
\hline$\sigma r \lambda$ & r/a & $0^{\circ}$ & \multicolumn{1}{|c|}{$20^{\circ}$} & $40^{\circ}$ & $60^{\circ}$ \\
\hline 1,00 & 0,00 & 0,00 & 0,00 & 0,00 \\
\hline 0,90 & 0,00 & 0,17 & 0,28 & 0,41 \\
\hline 0,80 & 0,00 & 0,38 & 0,62 & 0,93 \\
\hline 0,70 & 0,00 & 0,59 & 1,00 & 1,31 \\
\hline 0,60 & 0,00 & 0,35 & 0,72 & 1,04 \\
\hline 0,55 & 0,00 & 0,00 & 0,00 & 0,00 \\
\hline
\end{tabular}


SECTORIAL TIDES

\begin{tabular}{|l|l|l|l|l|}
\hline Orr r/a & $0^{\circ}$ & $20^{\circ}$ & $40^{\circ}$ & $60^{\circ}$ \\
\hline 1,00 & 0,00 & 0,00 & 0,00 & 0,00 \\
\hline 0,90 & 0,38 & 0,38 & 2,42 & 1,24 \\
\hline 0,80 & 0,55 & 0,48 & 0,35 & 1,41 \\
\hline 0,70 & 0,38 & 0,31 & 0,24 & 1,04 \\
\hline 0,60 & 0,35 & 0,28 & 0,21 & 0,10 \\
\hline 0,55 & 0,62 & 0,52 & 0,38 & 1,31 \\
\hline
\end{tabular}

\begin{tabular}{|c|c|c|c|c|}
\hline$\sigma r \varphi r / a$ & $0^{\circ}$ & $20^{\circ}$ & $40^{\circ}$ & $60^{\circ}$ \\
\hline 1,00 & 0,00 & 0,00 & 0,00 & 0,00 \\
\hline 0,90 & 0,00 & $-0,10$ & $-0,17$ & $-0,14$ \\
\hline 0,80 & 0,00 & $-0,28$ & $-0,41$ & $-0,41$ \\
\hline 0,70 & 0,00 & $-0,59$ & $-0,69$ & $-0,55$ \\
\hline 0,60 & 0,00 & $-0,31$ & $-0,59$ & $-0,45$ \\
\hline 0,55 & 0,00 & 0,00 & 0,00 & 0,00 \\
\hline
\end{tabular}

\begin{tabular}{|l|l|l|l|l|}
\hline$\sigma \varphi \varphi$ r/a & $0^{\circ}$ & $20^{\circ}$ & $40^{\circ}$ & $60^{\circ}$ \\
\hline 1,00 & 0,69 & 0,59 & 0,52 & $-0,10$ \\
\hline 0,90 & 1,97 & 1,83 & 1,38 & 0,93 \\
\hline 0,80 & 2,31 & 2,14 & 2,00 & 1,73 \\
\hline 0,70 & 2,17 & 2,17 & 2,31 & 2,45 \\
\hline 0,60 & 1,10 & 1,66 & 2,42 & 2,90 \\
\hline 0,55 & 0,00 & 0,00 & 0,00 & 0,00 \\
\hline
\end{tabular}

\begin{tabular}{|r|c|r|r|r|}
\hline$\sigma \varphi \lambda \mathrm{r} / \mathrm{a}$ & $0^{\circ}$ & \multicolumn{1}{|c|}{$20^{\circ}$} & \multicolumn{1}{c|}{$40^{\circ}$} & \multicolumn{1}{c|}{$60^{\circ}$} \\
\hline 1,00 & 0,00 & 0,00 & 0,00 & 0,00 \\
\hline 0,90 & 0,00 & $-0,59$ & $-1,10$ & $-1,73$ \\
\hline 0,80 & 0,00 & $-1,66$ & $-2,66$ & $-0,41$ \\
\hline 0,70 & 0,00 & $-2,66$ & $-4,07$ & $-6,62$ \\
\hline 0,60 & 0,00 & 0,00 & 0,00 & 0,00 \\
\hline 0,55 & 0,00 & 0,00 & 0,00 & 0,00 \\
\hline
\end{tabular}

\begin{tabular}{|r|r|r|r|r|}
\hline$\sigma \lambda \lambda \mathrm{r} / \mathrm{a}$ & \multicolumn{1}{|c|}{$0^{\circ}$} & \multicolumn{1}{c|}{$20^{\circ}$} & \multicolumn{1}{c|}{$40^{\circ}$} & \multicolumn{1}{c|}{$60^{\circ}$} \\
\hline 1,00 & 0,93 & 0,62 & 0,55 & 0,24 \\
\hline 0,90 & 1,38 & 1,14 & 0,41 & $-0,17$ \\
\hline 0,80 & 1,21 & 0,69 & $-0,17$ & $-0,86$ \\
\hline 0,70 & $-0,52$ & $-0,41$ & $-1,21$ & $-1,93$ \\
\hline 0,60 & $-3,62$ & $-3,69$ & $-3,76$ & $-3,80$ \\
\hline 0,55 & $-5,87$ & $-6,56$ & $-7,59$ & $-8,97$ \\
\hline
\end{tabular}

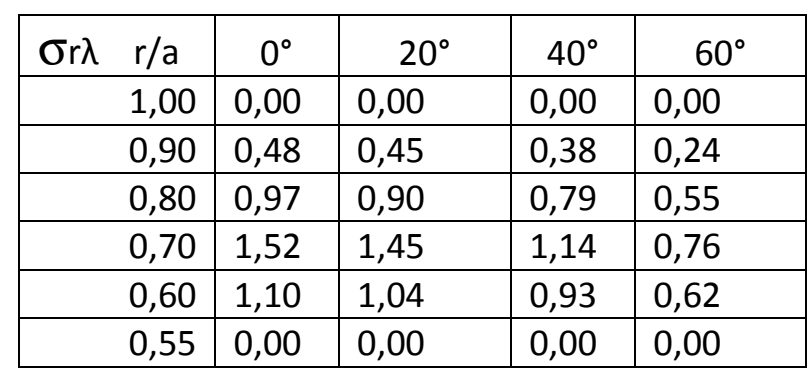

Table 2. Latitude dependence of the horizontal shear stress tensor components $\sigma_{\lambda \lambda}$ and $\sigma_{\varphi \varphi}$ at the Earth's

\begin{tabular}{|l|c|c|}
\hline ZONAL & $\sigma \varphi \varphi$ & $\sigma \lambda \lambda$ \\
\hline $0^{\circ}$ & $-1,83$ & 0,00 \\
\hline $20^{\circ}$ & $-0,41$ & 0,00 \\
\hline $40^{\circ}$ & 0,07 & 0,00 \\
\hline $60^{\circ}$ & 0,66 & 1,38 \\
\hline
\end{tabular}

\begin{tabular}{|l|l|l|}
\hline TESSERAL & $\sigma \varphi \varphi$ & $\sigma \lambda \lambda$ \\
\hline $0^{\circ}$ & 0,00 & 0,00 \\
\hline $20^{\circ}$ & 0,27 & 0,17 \\
\hline $40^{\circ}$ & 0,41 & 0,35 \\
\hline $60^{\circ}$ & 0,35 & 0,07 \\
\hline
\end{tabular}

\begin{tabular}{|l|r|r|}
\hline SECTORIAL & \multicolumn{1}{|c|}{$\sigma \varphi \varphi$} & \multicolumn{1}{c|}{$\sigma \lambda \lambda$} \\
\hline $0^{\circ}$ & 0,69 & 0,93 \\
\hline $20^{\circ}$ & 0,55 & 0,62 \\
\hline $40^{\circ}$ & 0,52 & 0,06 \\
\hline $60^{\circ}$ & $-1,04$ & 0,24 \\
\hline
\end{tabular}

surface in $\mathrm{kPa}$. 
Table 3. Distribution of vertical ( $\left.\sigma_{r r}\right)$ and horizontal $\left(\sigma_{\theta \theta}\right)$ load stress components (in $\mathrm{kPa}$ ) at the surface in function of angular distance from the centre of the loaded area $10^{\circ} \times 10^{\circ} .1 \mathrm{~m}$ high water column load is considered.

\begin{tabular}{|c|r|r|}
\hline$\Theta$ & $\sigma r r$ & $\sigma \ominus \Theta$ \\
\hline $0^{\circ}$ & 1,14 & 0,48 \\
\hline $5^{\circ}$ & 0,62 & 0,35 \\
\hline $10^{\circ}$ & $-0,10$ & 0,17 \\
\hline $15^{\circ}$ & 0,00 & 0,00 \\
\hline $20^{\circ}$ & 0,07 & $-0,03$ \\
\hline $25^{\circ}$ & 0,03 & 0,00 \\
\hline $30^{\circ}$ & 0,03 & 0,00 \\
\hline
\end{tabular}

